\title{
A THEORETICAL FRAMEWORK FOR ANALYZING OF THE POSTSECULAR WORLD (REVIEW ON BOOKS BY D.A. UZLANER "THE END OF RELIGION? THE HISTORY OF THE SECULARIZATION THEORY" AND "POSTSECULAR TURN. HOW TO THINK ABOUT RELIGION IN THE $21^{\text {st }}$ CENTURY")
}

\author{
Evgeniy V. Karchagin \\ Volgograd State Technical University, Volgograd, Russian Federation
}

\begin{abstract}
This review presents an analysis of two books by D.A. Uzlaner: "The End of Religion? The History of the Secularization Theory" (2019) and "Postsecular Turn. How to Think About Religion in the $21^{\text {st }}$ Century" (2020), in which a successful attempt was made to delineate the field of modern discussions about the secular and post-secular world and the position of religious phenomena in modern society. In "The End of Religion? The History of the Secularization Theory" the author explores the prerequisites and formation of the theory of secularization. The structure of the chapters is based on the periodization, which includes the background, formation, criticism and renewal, crisis and decline of the theory of secularization. "Postsecular Turn. How to Think About Religion in the $21^{\text {st }}$ Century" is not a historical research. It is an attempt to build a new theory of secularization, the need for which was justified in the first book. The cross-cutting theme of the book is the ratio of religious and nonreligious in the public space. The most notable in this monograph are the elaboration of various details of the optics of the description of the post-secular world and its origins, as well as an analysis of the current situation in Russia of the last decade. Due to the methodological balance and critical premise in the "Kantian" sense, the cartography of the religious and non-religious in the dilogy brings us closer to understanding of the contradictory Modern terrain. The author bases his analysis both on the classics of social thought and on the latest researchers. The proposed theoretical framework clarifies the specifics of religiosity and related phenomena in the current situation both in the global scale and in Russia.
\end{abstract}

Key words: Uzlaner, secularization, postsecular turn, religion, postreligion, sociology of religion.

Citation. Karchagin E.V. A Theoretical Framework for Analyzing of the Postsecular World (Review on Books by D.A. Uzlaner "The End of Religion? The History of the Secularization Theory" and "Postsecular Turn. How to Think About Religion in the $21^{\text {st }}$ Century"). Logos et Praxis, 2021, vol. 20, no. 3, pp. 43-48. (in Russian). DOI: https:// doi.org/10.15688/lp.jvolsu.2021.3.5 
УДК $316.75(049.32)$

ББК 60.563.0я4

\title{
ТЕОРЕТИЧЕСКАЯ РАМКА ДЛЯ АНАЛИЗА ПОСТСЕКУЛЯРНОГО МИРА (РЕЦЕНЗИЯ НА КНИГИ Д.А. УЗЛАНЕРА «КОНЕЦ РЕЛИГИИ? ИСТОРИЯ ТЕОРИИ СЕКУЛЯРИЗАЦИИ» И «ПОСТСЕКУЛЯРНЫЙ ПОВОРОТ. КАК МЫСЛИТЬ О РЕЛИГИИ В ХХІ ВЕКЕ»)
}

\author{
Евгений Владимирович Карчагин \\ Волгоградский государственный технический университет, г. Волгоград, Российская Федерация
}

\begin{abstract}
Аннотация. В рецензии представлен анализ двух книг Д.А. Узланера: «Конец религии? История теории секуляризации» (2019) и «Постсекулярный поворот. Как мыслить о религии в XXI веке» (2020), в которых была предпринята успешная попытка расчертить поле современных дискуссий о секулярном и постсекулярном мире, о положении и роли религиозных феноменов в современном обществе. В монографии «Конец религии? История теории секуляризации» автор исследует предпосылки и становление теории секуляризации. Структура глав книги выстроена с опорой на разработанную периодизацию, которая включает в себя предысторию, становление, критику и обновление, кризис и упадок теории секуляризации. Монография «Постсекулярный поворот. Как мыслить о религии в XXI веке» не носит исторического и обзорного характера. Она является попыткой выстроить новую теорию секуляризации, необходимость которой была обоснована в первой книге. Сквозная тема книги - соотношение религиозного и нерелигиозного в публичном пространстве. Наиболее ценным в данной монографии можно считать проработку различных деталей оптики описания постсекулярного мира и его истоков, а также добротный анализ актуальной российской ситуации последних десяти лет. Благодаря методологической взвешенности и критическому в «кантианском» смысле посылу, представленная в дилогии картография религиозного и нерелигиозного однозначно приближает нас к пониманию противоречивой современной местности. Автор основывает свой анализ и на классиках социальной мысли, и на новейших исследовательских разработках. Предложенная им теоретическая рамка позволяет прояснить специфику религиозности и смежных явлений в современной ситуации как в мире, так и в России.

Ключевые слова: Узланер, секуляризация, постсекулярный поворот, религия, пострелигиозность, социология религии.

Цитирование. Карчагин Е. В. Теоретическая рамка для анализа постсекулярного мира (Рецензия на книги Д.А. Узланера «Конец религии? История теории секуляризации» и «Постсекулярный поворот. Как мыслить о религии в XXI веке») // Logos et Praxis. - 2021. - T. 20, № 3. - C. 43-48. - DOI: https://doi.org/10.15688/ lp.jvolsu.2021.3.5
\end{abstract}

Две рецензируемые книги Д.А. Узланера: «Конец религии? История теории секуляризации» [Узланер 2019] и «Постсекулярный поворот. Как мыслить о религии в XXI веке» [Узланер 2020], хотя и не позиционируются так автором, образуют собой дилогию. После их прочтения можно утверждать, что данной дилогией автор однозначно претендует на место главного в России специалиста по проблемам (пост-)секулярного общества. Текст рецензии не содержит критических суждений, его цель - показать сильные стороны данного проекта и привлечь к нему внимание заинтересованного научного сообщества и широкой аудитории.
Как следует из названия, в первой книге «Конец религии? История теории секуляризации» автор исследует предпосылки и становление теории секуляризации. То есть перед нами не книга о феномене секуляризации, а очерк, фиксирующий взлет и падение социологической теории секуляризации. Нам предлагается погрузиться в историю формирования теории, которую автор называет «основной парадигмой социологии религии на протяжении последних 100 лет» [Узланер 2019, 9]. Эта книга - добротный, насыщенный исторический обзор, который охватывает все основные этапы (включая экскурс в советский опыт) теоретизирования секулярного. Автор выде- 
ляет предысторию, становление, этапы критики и обновления, кризиса и упадка. В соответствии с этой периодизацией он выстраивает и структуру книги.

Описав первые наброски (в философии эпохи Просвещения и в немецкой классической философии) и более или менее полноценные попытки (у К. Маркса) создать теорию секуляризации, автор обращается к классикам социологической мысли (Дюркгейм, Тённис). Анализ предыстории теории секуляризации завершается фигурой М. Вебера, которая оказывается ключевой. «Сохранение формы религиозного явления при одновременном упадке и забвении его религиозного содержания есть тот процесс, который Вебер называет секуляризацией» [Узланер 2019, 30]. Веберовская «тенденция будет наблюдаться в теориях второй половины XX в.: секуляризация будет фиксироваться как объективный процесс, но при этом рефреном будет звучать мотив о ее не совсем благоприятных последствиях для человека и общества» [Узланер 2019, 31]. Собственно говоря, как отмечает автор, научным это понятие стало, когда благодаря Веберу лишилось аксиологической нагрузки [Узланер 2019, 12].

Вторая глава описывает становление теории секуляризации в 60-е гг., когда «секуляризация превращается в ключевую социологическую проблему и дискуссиям о ней начинает уделяться все больше и больше внимания» [Узланер 2019, 36]. Эти дискуссии опираются в основном на эмпирическую почву США, где религия утратила институциональную тотальность и перешла в частную сферу, то есть приватизировалась. Приватизация религии сопровождается при этом маркетизацией, бюрократизацией и стандартизацией, что приводит к тому, что «формы религии, распространенные в современном обществе, более не опираются ни на какой институциональный базис, их главная опора - “частная сфера” жизни индивида, а также те эмоции и сантименты, которые вызывают у него религиозные символы. Безусловно, религиозные институты могут по-прежнему существовать, однако их роль вторична, отныне они лишь обслуживают религиозные потребности индивидов» [Узланер 2019, 94]. При этом теории этого периода не едины в своем понимании секуляризации: «в существу- ющих теориях под секуляризацией понимаются три различных процесса: лаицизация (изменение положения религии на уровне структуры общества), религиозные изменения и изменения индивидуальной религиозности» [Узланер 2019, 112].

Третья и четвертая главы посвящены кризису теории секуляризации и описанию ее судьбы в последние десятилетия. Автор выделяет ядро (базис) и надстройку теории. Ядро теории автор видит «в тезисе об универсальных закономерностях развития обществ, вступивших на путь модернизации» [Узланер 2019, 114]. Критика в 80-е и 90-е гг. затрагивала надстройку теории. При этом, большинство критических возражений оказались несостоятельны, равно как и попытка обновления теории (Лечнер, Чавес, Казанова, Йамейн). Однако ценность пересмотра в 90-е гг. помимо прочего состоит том, что: «Был исправлен самый очевидный изъян теории: тезис о том, что секуляризация приводит к упадку религии и религиозности как таковой» [Узланер 2019, 145]. Фатальной для ядра теории секуляризации стала концепция «множественных современностей» (multiple modernities) Шмуэля Эйзенштадта (1923-2010). Эта концепция стала ключевой для многих исследователей: «концепция множественных современностей позволяет поставить вопрос в том числе и об обратном влиянии: как религия не просто влияет, но зачастую определяет те конкретные формы, которые принимает современность. Ведь в конечном счете именно религиозные традиции определяют цивилизационный контекст, на который накладывается та или иная разновидность программы современности» [Узланер 2019, 160]. Последующие попытки отстаивать теорию в классическом виде (К. Доббелере, С. Брюс) не позволяют ее спасти. Д. Мартин, Х. Казанова, П. Бергер уже в полной мере осознают следствие концептуального тупика: «В их работах заметен поиск того, что когда-нибудь в будущем может стать основанием новой теории секуляризации» [Узланер 2019, 176]. При этом новая теория секуляризация должна принимать во внимание именно плюрализм текущей социальной реальности: «Секуляризаций может быть столько же, сколько может быть сплетений различных политических режимов, религиозных 
традиций, идейных исканий, социальных предпосылок и т. д.» [Узланер 2019, 184].

В пятой главе автор касается «советской теории секуляризации». Минус советских работ автор усматривает в некритичном использовании идей классиков, в то время как на Западе не боялись их критиковать. «Кроме того, на Западе социологические теории секуляризации сразу же оказались под огнем пусть и не всегда справедливой, но все же содержательной критики со стороны религиозных мыслителей и других скептически настроенных авторов. Именно такой критики не хватало советской модели» [Узланер 2019, 189]. Однако плюс заключается в том, что советские теории явно демонстрировали свои философские основы, в отличие от западных теоретиков, которые критиковались за философскую наивность.

В Заключении автор утверждает, что теория из «основной парадигмы социологии религии» в конечном итоге «превратилась во второстепенное явление» [Узланер 2019, 206]. Распад парадигмы тем не менее не был абсолютным. Некоторые ее элементы, фиксирующие современное положение религии в обществе, не стоит сбрасывать со счетов: «Эти наблюдения - касающиеся, например, плюрализма, рынка религий, релятивизации имеют ценность сами по себе, безотносительно к тому концептуальному каркасу, в который они были некогда вмонтированы» [Узланер 2019, 207]. Наконец, в Приложении («Секуляризация как социологическое понятие») мы имеем, по сути, краткую сводку текста монографии и возврат к истокам теории секуляризации, а именно веберовскому методологическому пониманию секуляризации как аксиологически нейтрального инструмента: «секуляризация как социологическое понятие прежде всего нейтральная описательная категория, обозначающая процесс утраты религией своей социальной значимости. При этом речь идет именно о социальной значимости, а не о большей или меньшей религиозности и не о ее качестве» [Узланер 2019, 221]. Так, религиозность мы с его помощью изучать не можем.

Первая книга ценна не только тем, что в ней представлена история теории, в ней показана и ее трансформация в результате кри- тики со стороны ее противников. Чтение интересно и не специалисту, поскольку позволяет понять многие процессы, которые протекают в поле взаимоотношений религии и других социальных институтов, понять причины трансформации современной религиозности и упадка влияния традиционных религий, в частности, христианства на общественную жизнь современных государств. Книга также очерчивает теоретическое поле, которое предшествовало наиболее актуальным современным дискуссиям о пост- и десекуляризованном мире, и хорошо показывает, что современное обсуждение проблем постекулярной эпохи не растет из ниоткуда.

Вторая книга - «Постсекулярный поворот. Как мыслить о религии в XXI веке»-уже не носит исторического и обзорного характера. Текст книги представляет собой сборник статей (два текста написаны в соавторстве с Кристиной Штекль), объединенных общей темой - постсекулярностью как новой реальности и проблемами ее репрезентации. Так, здесь мы видим попытку выстроить новую теорию секуляризации, необходимость которой была обоснована в первой книге. Сквозная тема книги - соотношение религиозного и нерелигиозного в публичном пространстве. Кроме того, автор очерчивает ситуацию, которая сложилась в постсоветской России. Эту книгу можно назвать проблемной частью дилогии. Она построена на характеристике текущего положения дел в реальности и насыщена анализом интересных кейсов. В отличие от первой книги, здесь описываются уже не столько исторические перипетии теории, сколько затрагиваются реальные социальные изменения и вопросы оптики их адекватного теоретического описания. Такое построение книги неизбежно приводит к тому, что некоторые сюжеты встречаются в нескольких главах. Однако следует отметить, что такие повторения не являются дословными и позволяют оттенить и прояснить необходимые детали. Так, здесь мы встречаем практически тот же перечень анализируемых авторов, что и в первой: Ч. Тейлор, Дж. Капуто, Дж. Милбанк, Ш. Эйзеншдат и другие (К. Пиксток), чьи идеи теперь фигурируют не в хронологическисистематическом порядке, как уже было отмечено, а как необходимый фон актуальной 
дискуссии о месте религии в общественном порядке. Особое место при этом занимают Дж. Ролз и Ю. Хабермас как фигуры, разметившие и проблематизировавшие публичное пространство плюралистического общества.

Наиболее содержательно ценным в этой книге я считаю два момента. Первый заключается в более глубокой проработке различных деталей оптики описания постсекулярного мира и его истоков. Отмечу, в частности, анализ интеллектуальных предпосылок создателей секулярного мира модерна в поздней схоластике, включая теорию унивокальности Дунса Скотта (понимание творения как вида бытия наряду с Богом), которая может быть понята как фундамент новоевропейского секуляризма [Узланер 2020, 67-70].

Второй ценный момент заключается в добротном анализе актуальной российской ситуации последних десяти лет. Автор вводит понятие «постсекулярные гибриды», которое позволяет, используя, например, кейс «Пусси Райот» в нескольких главах, показать сложность сборки секулярного и религиозного в нашей стране. В этом контексте также интересна глава о проблематичности проправославного консенсуса и отсутствии прорелигиозного консенсуса в России. Автор учитывает и анализирует различные интересные и громкие кейсы в православной среде, включая феномен «бывших верующих» (М. Кикоть, проект «Ахилла» бывшего священника Волгоградской епархии А. Плужникова и др.). Закономерный итог процессов последнего десятилетия в том, что «российское православие более не является фактором национального консенсуса. Оно становится фактором национального конфликта, еще одним расколом, разделяющим российскую нацию» [Узланер, 2020, 345]. Разные скандальные и конфликтные ситуации как в церковной сфеpe, так и в сфере церковно-государственных отношений получают необходимое взвешенное объяснение. Как человек, имевший одновременно опыт активной церковной жизни, и опыт академической жизни, могу отметить, что тексты Узланера представляют подход, который, принимая во внимание самые разные проблемные стороны религиозной жизни, дает им взвешенную и методологически ценную интерпретацию.
Последнее стало возможным, на мой взгляд, благодаря методологической обоснованности разработок автора. В целом в текстах Узланера очевиден методологический посыл. Благодаря этому дилогия автора утверждает в русскоязычной науке новое положение дел, практически совершает «коперниканский поворот» в науках о религии. Она показывает сложность и противоречивость современной религиозной ситуации в разных местах планеты, религии, которую необходимо рассматривать в новом контексте - постсекулярном. Если этот поворот мы сравниваем с «коперниканским», то есть смысл вспомнить и «кантианский проект», обозначивший границы научного познания. В этой дилогии мы получили добротный качественный и критический в кантианском смысле анализ религии. Автор на базе ключевых теоретиков секулярности и своего собственного анализа общемировой и российской ситуации обозначил границы религии и одновременно того, что ей сегодня не является в публичной сфере. Автор «ограничил» религию, чтобы дать место секулярному и, наоборот, «ограничил» секулярное, чтобы дать место религии. Представленная картография религиозного и нерелигиозного однозначно приближает нас к пониманию противоречивого актуального положения вещей.

Отмечу здесь один важный факт современной эпохи, который показывает автор: «парадокс современных обществ в том, что они оказываются лишенными единого «символического универсума». Современные общества характеризует плюрализм, когда одновременно сосуществует несколько противоположных символических универсумов, каждый из которых связан со своим небольшим сегментом» [Узланер 2019, 68]. Из-за этого так трудно сегодня вести дискуссии о фундаментальных социально-политических ценностях свободы, равенства, демократии и др. Так, мировоззренческий и идеологический раскол особенно ярко отражается на дискуссиях о проблеме справедливости. Заслуга автора в том, что придерживаясь «идеологии» Нового Просвещения [Узланер 2020, 209-211], автор успешно смог расколдовать уже сам Модерн как новую религию, и объяснить существенные стороны расколотости постсовременного мира. Если все знание социально обуслов- 
лено, то за позицией Милбанка, Узланера и других «позитивистов»-постсекуляристов, мы видим принципы старого доброго философского рационализма, не утратившего свой потенциал универсального символического универсума.

Обе книги написаны очень хорошим, ясным научным языком, что можно объяснить многолетним опытом редакторской работы (автор с 2012 г. является главным редактором журнала «Государство, религия, церковь в России и за рубежом») и публицистической активностью автора. Опечатки встречаются в основном в первой книге, вторая книга вычитана значительно лучше.

Итак, книги ценны тем, что дают актуальную теоретическую рамку понимания специфики религиозности в современной ситуации как в мире, так и в России. Автор основывает свой анализ и на классиках социальной мысли и на новейших исследовательских разработках. При этом особенно ценным является опыт осмысления российских процессов и анализ важнейших кейсов последних лет. Аналогов такого рода исследований в российской науке сейчас нет, и при этом автору удалось преодолеть опасность научного локализма и встроиться в актуальную международную дискуссию, о чем свидетельствует, в частности, публикация частей второй книги в авторитетных зарубежных изданиях на английском языке. Современные российские ученые из социально-гуманитарных дисциплин часто оказывается в западне разных модных «поворотов», которые состоялись в академическом мире зарубежья, и пишут тексты-пересказы описательного характера. Весьма отрадно, что книги являются не простым вторичным пересказом модных западных теорий, но предлагают свой оригинальный, чувствительный к деталям и методологически отрефлексированный взгляд.

\section{СПИСОК ЛИТЕРАТУРЫ}

Узланер 2019 - Узланер Д.А. Конец религии? История теории секуляризации. М.: Издат. дом ВШЭ, 2019.

Узланер 2020 - Узланер Д.А. Постсекулярный поворот. Как мыслить о религии в XXI веке. М.: Изд-во Ин-та Гайдара, 2020.

\section{REFERENCES}

Uzlaner D.A., 2019. The End of Religion? History of the Secularization Theory. Moscow, Izdatel'skij dom Vysshej shkoly ekonomiki.

Uzlaner D.A., 2020. The Postsecular Turn: How to Think on Religion in $21^{\text {st }}$ Century. Moscow, Izdvo In-ta Gaidara.

\section{Information About the Author}

Evgeniy V. Karchagin, Doctor of Sciences (Philosophy), Professor, Department of Philosophy, Sociology and Psychology, Volgograd State Technical University, Academicheskaya St, 1, 400074 Volgograd, Russian Federation, evgenkar@yandex.ru, https://orcid.org/0000-0001-7398-9292

\section{Информация об авторе}

Евгений Владимирович Карчагин, доктор философских наук, профессор кафедры философии, социологии и психологии, Волгоградский государственный технический университет, ул. Академическая, 1, 400074 г. Волгоград, Российская Федерация, evgenkar@yandex.ru, https://orcid.org/0000-0001-7398-9292 